\title{
Methane discharge from a deep-sea submarine mud volcano into the upper water column by gas hydrate-coated methane bubbles
}

\author{
Eberhard J. Sauter ${ }^{\mathrm{a}^{*}}$, Sergey I. Muyakshin ${ }^{\mathrm{b}}$, Jean-Luc Charlouc ${ }^{\mathrm{c}}$, Michael Schlüter ${ }^{\mathrm{a}}$, \\ Antje Boetius $^{d}$, Kerstin Jerosch ${ }^{a}$, Ellen Damm ${ }^{a}$, Jean-Paul Foucher ${ }^{c}$ and Michael Klages ${ }^{a}$ \\ ${ }^{a}$ Alfred Wegener Institute for Polar and Marine Research, Am Handelshafen 12, 27570 Bremerhaven, Germany \\ Institute of Applied Physics of the Russian Academy of Sciences, 46 Uljanov Str., 603950 Nizhnii Novgorod, \\ Russian Federation \\ 'Department of Marine Geosciences, IFREMER Centre de Brest, DRO/GM, BP 70, Plouzane Cedex 29280, \\ France \\ ${ }^{\mathrm{d} M a x}$ Planck Institute for Marine Microbiology, 28359 Bremen, Germany
}

*: Corresponding author : Tel.: +49 4714831 1517; fax: +49 4714831 1425. esauter@awi-bremerhaven.de

\begin{abstract}
The assessment of climate change factors includes a constraint of methane sources and sinks. Although marine geological sources are recognized as significant, unfortunately, most submarine sources remain poorly quantified. Beside cold vents and coastal anoxic sediments, the large number of submarine mud volcanoes (SMV) may contribute significantly to the oceanic methane pool. Recent research suggests that methane primarily released diffusively from deep-sea SMVs is immediately oxidized and, thus, has little climatic impact.

New hydro-acoustic, visual, and geochemical observations performed at the deep-sea mud volcano Håkon Mosby reveal the discharge of gas hydrate-coated methane bubbles and gas hydrate flakes forming huge methane plumes extending from the seabed in $1250 \mathrm{~m}$ depth up to $750 \mathrm{~m}$ high into the water column. This depth coincides with the upper limit of the temperature-pressure field of gas hydrate stability. Hydrographic evidence suggests bubble-induced upwelling within the plume and extending above the hydrate stability zone. Thus, we propose that a significant portion of the methane from discharged methane bubbles can reach the upper water column, which may be explained due to the formation of hydrate skins. As the water mass of the plume rises to shallow water depths, methane dissolved from hydrated bubbles may be transported towards the surface and released to the atmosphere. Repeated acoustic surveys performed in 2002 and 2003 suggest continuous methane emission to the ocean. From seafloor visual observations we estimated a gas flux of $0.2(0.08-0.36)$ mol s-1 which translates to several hundred tons $\mathrm{yr}-1$ under the assumption of a steady discharge. Besides, methane was observed to be released by diffusion from sediments as well as by focused outflow of methane-rich water. In contrast to the bubble discharge, emission rates of these two pathways are estimated to be in the range of several tons $\mathrm{yr}-1$ and, thus, to be of minor importance. Very low water column methane oxidation rates derived from incubation experiments with tritiated methane suggest that methane is distributed by currents rather than oxidized rapidly.
\end{abstract}

Keywords: methane sources; plume; methane budget; submarine mud volcanoes; gas bubbles; gas hydrates; hydro-acoustics 


\section{Introduction}

The contribution of methane to current global warming is estimated to be about $15 \%$ [1]. Thus, constraining the sources and sinks of this important greenhouse gas whose atmospheric concentration is still increasing, is critical to improve climate predictions. As part of the global carbon cycle, enormous quantities of methane occur in marine sediments. One mechanism to release methane from the sediment to the ocean is through submarine mud volcanism. However, the mechanisms and fate of this discharge as well as its quantification are poorly constrained. Worldwide, $10^{3}-10^{5}$ submarine mud volcanoes (SMVs) are believed to store $10^{10}-10^{12} \mathrm{~m}^{3}$ of methane $\left(54-5400 \mathrm{Mt}\right.$ of carbon; $1 \mathrm{Mt}=10^{6}$ million metric tons) in associated gas hydrates [2]. Although, this is of minor importance compared to the estimated $10^{4} \mathrm{Gt}$ of methane-carbon world-wide in gas hydrates, which primarily occurs at continental margins [3], SMVs are estimated to release about $27 \mathrm{Mt}$ methane $\mathrm{yr}^{-1}$ to the ocean [4]. Many approaches have been undertaken to study methane discharge from SMVs and other cold seeps such as decomposing gas hydrates. Depending on ambient biogeochemical conditions, methane can rapidly dissolve and oxidize close above the seafloor $[5,6,7]$. This supports the conclusion, that methane from oceanic

sources contributes little to atmospheric methane budgets, i.e. 5-15 $\mathrm{Gt} \mathrm{yr}^{-1}$ compared to a

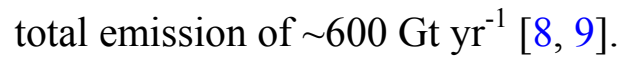

However, there is also evidence that methane may not oxidize in the higher water column for time scales of several years to decades $[5,10]$. Oxidation rates are linked to parameters such as temperature, pressure, and substrate availability in the water column [11]. In addition, bubble discharge is a mechanism that can efficiently transfer methane not only 
from shallower hydrocarbon seep sites [e.g. 12] but also from water depths greater than $2000 \mathrm{~m}$ to upper water layers $[13,14,15,16]$. Evidence also exists for deep seep sites. Gas plumes were surveyed by acoustic means using transducer frequencies between 4 and 110 $\mathrm{kHz}$ [13-16]. There are also approaches to quantify the amount of gas release from hydroacoustic records $[17,18]$ as well as from visual bubble observations [19]. Rising bubbles were observed to be protected against rapid dissolution by gas hydrate coating if released within the temperature-pressure field of gas hydrate stability [20, 21]. Rising bubble plumes induce an upwelling flow which further increases the vertical velocity of the bubbles and also accelerates the surrounding water [12, 19, 22].

Here we present results from a multi-method approach obtained at the Håkon Mosby Mud Volcano (HMMV) suggesting that considerable gaseous methane is released at $1250 \mathrm{~m}$ water depth and rises to the upper water column as hydrate-coated bubbles. Although subsequent to its discovery in 1989/1990 [23], various visual observations were performed by manned and unmanned underwater vehicles [24, 25], no bubble gas emissions had been observed [26, 27]. Instead it was assumed, that the methane released predominantly is dissolved in vent fluids and rapidly oxidized in the lower water column [26]. However, based on the results of our hydroacoustic, hydrographic, geochemical, and visual observations, we further propose that bubble emissions occur and generate an upwelling flow that may vertically transport plume water enhanced with dissolved methane above the gas hydrate stability zone. Accordingly, methane dissolved from the plume may transfer to surface waters and thus, potentially be released to the atmosphere. Data presented here suggest the need to reassess the contribution of deep-sea gas seeps such as submarine mud 
volcanoes and gas hydrate deposits to atmospheric methane budget and the global climate cycle.

\section{Regional setting}

The Håkon Mosby Mud Volcano (HMMV) is a structure $\sim 1.5 \mathrm{~km}$ in diameter, situated in $1250 \mathrm{~m}$ water depth at the Norwegian-Barents-Spitzbergen continental margin (Fig. 1). The HMMV is relatively well known due to numerous investigations [e.g. 26, 27, 28] and has been proposed as characteristic of other deep-sea SMVs $[4,26]$ with respect to methane seepage. The formation of the HMMV presumably happened concomitant with an earth quake-triggered submarine land slide during the Late Pleistocene, 330-200 ka before present [29, 30]. Today, fluidized sediments are expelled from HMMV's interior to the seafloor along with large amounts of methane [26]. The central area is characterized by high thermal gradients and outcropping of fresh gray muds. In contrast, the outer regions are covered by chemosynthetic communities dependent on diffusive methane and sulfide fluxes from below $[4,31]$. Diffusive discharge to the deep-sea occurs where methane is not completely oxidized by microbial methanotrophs [32, 33, 34]. High methane oxidation rates were found at the sediment surface [35].

The hydrographic regime above the HMMV is determined by the Norwegian Atlantic Current which carries Atlantic Water along the Norwegian-Barents-Spitzbergen continental margin to the north in the upper $600 \mathrm{~m}$ of the water column. Arctic Intermediate Water flows beneath this water body. A more detailed description of the geologic and oceanographic setting of HMMV is given in Refs. [26] and [33], respectively. 


\section{Methods and materials}

\section{Field campaigns}

Field data were acquired during the two expeditions ARK XVIII/1b (30.7.-24.8.2002, Longyearbyen-Tromsø), and ARK XIX/3b (20.6.-19.7.2003, Tromsø- Tromsø) with RV "Polarstern". During the ARK XIX/3b in situ observations and sampling were performed with the ROV "Victor 6000".

Acoustic images of water column methane plumes: Echograms were obtained by a shipborn Simrad ${ }^{\mathrm{TM}}$ EK60 echo sounder in 2002 (Fig. 3a), and 2003 (Fig 3b). The relevant echo sounder frequency was $38 \mathrm{kHz}$. The system was characterized by a beam width of $7.1^{\circ}$, a pulse duration of $4 \mathrm{msec}$, and a spatial resolution of $\sim 3 \mathrm{~m}$. The repetition period was selected to be $3 \mathrm{sec}$ and the electrical power output was $2000 \mathrm{~W}$. Echograms show the volume backscattering section in the range of -80 to $-34 \mathrm{~dB} \mathrm{re} \mathrm{m}^{-1}$ whereat the unit represents the volume backscattering coefficient measured in decibels referenced to 1 steradian $\left(=1 \mathrm{~m}^{2} \mathrm{~m}^{-3}=1 \mathrm{~m}^{-1}\right)$. The ship's speed during acoustic surveys was 1.5 to 2 knots equivalent to $0.8-1.0 \mathrm{~m} \mathrm{~s}^{-1}$.

Visual observations of bubble discharge: At the sea floor the ROV "Victor 6000" was navigated by up to 7 video cameras, of which 4 were recorded to DVD. The best quality sequences were obtained by a 3-CCD TV camera (Sony ${ }^{\mathrm{TM}}$ DXC 990 P), which could be maneuvered by an electric motor. Still photographs were taken with a Sony Cybershot ${ }^{\mathrm{TM}}$ digital still camera mounted above the ROV's main video camera.

Image analysis was performed with the software package AnalySIS Pro version 3.0 (Soft Imaging System $\mathrm{GmbH}$ ). Contrast and background optimized digital still images were 
converted to binary format for determination of bubble size distribution. Size calibration was done by comparison with objects of known dimensions in the field of view, e.g. sampling tools or parts of the ROV. Although high quality images were obtained from the video and still cameras with a field of view size on a meter scale, bubbles, one to several millimeters in diameter were depicted close to the pixelation size limit. Therefore, there is considerable uncertainty in bubble size, which we estimate was $\pm 1 \mathrm{~mm}$ in diameter. Correspondingly, this introduces a large uncertainty into the bubble volume, especially for small bubbles, since it varies as the radius cubed. Additional uncertainty arises from the observation angle which was not perpendicular to the bubble stream since the ROV had to be positioned on a hummocky, uneven seafloor close to the bubble seep. Therefore, an average calibration scale was estimated from comparison with objects of known size. Due to these uncertainties, we simplified the calculation of the bubble volume to spherical instead of ellipsoidal shaped bubbles $[22,36]$. To account for the uncertainties in the volume determination, the bubble volume was calculated for bubble size distributions as obtained by image analysis but also for the bubble radii $\pm 0.5 \mathrm{~mm}$ as lower and upper limits, respectively.

Similar uncertainties affect the determination of bubble rise velocities. Beside the angled view of the plume tilted by the bottom current, the bubble discharge appeared to be pulsed. Thus it was difficult to derive exact values. A mean bubble rise velocity was estimated from a number of individual measurements. Rise velocity strongly depends on bubble size [19] and density, which are affected by surface state, the presence and thickness of a gas hydrate skin as well as by possible sediment inclusions. 
Hydrographic measurements: A Sea-Bird Electronics ${ }^{\mathrm{TM}} \mathrm{CTD}^{1}$ (SBE911plus) was used together with a rosette water sampler (SBE-32) for hydrographic measurements. Temperature was cross calibrated against a high-precision thermometer (SBE35) during bottle closure while remaining $\sim 2-3$ minutes at constant depth. Salinity was inter-calibrated against salinity measurements of water samples with a lab salinometer (Guildline 8400B). Calibration is further described in ref. [37]. For transmission and optical backscatter measurements a C-Star Wet $\mathrm{Lab}^{\mathrm{TM}}$ transmissiometer and a SeaTech ${ }^{\mathrm{TM}}$ nephelometer were attached to the CTD probe.

Methane analyses: Methane concentrations were analyzed onboard by headspace technique from unpoisoned water samples immediately after retrieval. Analyses were performed according to [38] using a Trace GC (ThermoFinnigan) equipped with a PorapakQ column and a flame ionization detector. In addition, methane was analyzed by a purge and trap technique from $\mathrm{NaN}_{3}$ poisoned subsamples immediately after the cruise according to Refs. [39] and [40]. Gas loss due to decompression during sample retrieval was negligible since even the highest methane concentrations $\left(126 \mu \mathrm{mol} \mathrm{L}^{-1}\right)$ were one order of magnitude below the seawater methane solubility under surface conditions $\left(\sim 1.5 \mathrm{mmol} \mathrm{L}^{-1}\right.$, calculated according to [41]). Correspondingly, bubble degassing was not observed in

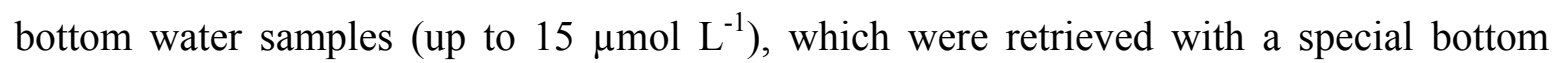
water sampler equipped with transparent bottles [34, 42] (data not shown).

\footnotetext{
${ }^{1}$ Oceanographic conductivity, temperature, depth profiler
} 


\section{Methane oxidation rates:}

Potential microbial methane oxidation rates in the water column above the HMMV were determined by incubating replicate water samples with tritiated methane $(5 \mu \mathrm{M}$ end concentration) according to a method adapted from Ref. [5]. Water samples were retrieved by ROV, or bottom water sampler from bottom waters $(0.1-1 \mathrm{~m})$, or by rosette water sampler from $4 \mathrm{~m}$ above the seabed to the surface. Samples were incubated for 4 days following the addition of tritiated methane. At the end of the incubation any microbially mediated methane oxidation was stopped by formalin addition (to a final concentration of $2 \% \mathrm{v} / \mathrm{v})$. Un-reacted tritiated methane was removed by purging the samples with watersaturated methane and the remaining oxidation product, tritiated water, was quantified by liquid scintillation counting. A set of controls was prepared by adding formalin before incubation and treated in the same manner.

Flow measurements: Advective fluid discharge was estimated by ROV-based vertical flow measurements using an acoustic 3-axis travel-time flow meter (Nobska, MAVS3). The measurement principle and a description of the device is presented in Ref. [43]. The method allows measurement of very low flow velocities (range $0.3-200 \mathrm{~cm} \mathrm{~s}^{-1}$ ) with an accuracy of $0.3 \mathrm{~cm} \mathrm{~s}^{-1}$ and a resolution of $0.03 \mathrm{~cm} \mathrm{~s}^{-1}$. Since gas bubbles strongly affected the measurements acoustically and by gas hydrate precipitation on the device, only data obtained from gas bubble-free fluid discharge sites were considered. 


\section{Results and discussion}

Several locations with active methane and mud seepage were video recorded at the northern part of the HMMV's center during video surveys in 2003 with the ROV "Victor 6000" (Fig. 2a). Here, a steady but pulsing bubble discharge was observed escaping from open faults. This area was hummocky and partly covered by patches of bacterial mats and populated by pogonophorans. The seabed was also partially exposed. High geothermal gradients with temperatures of up to $25^{\circ} \mathrm{C}$ at $20 \mathrm{~cm}$ below the seafloor [44] cause rapid changes in the methane stability field within the sediment surface. As a result, bubbles in the warm geofluids rapidly become covered by hydrate upon release to the cold bottom water $\left(-0.9^{\circ} \mathrm{C}\right)$. This was visually supported be trapping some bubbles in a transparent tube (push core) which instantly formed porous gas hydrate. Gas bubbles were more ellipsoidal than lenticular in shape (Fig. 2b) which also suggests a hydrate coating [13, 15, 21]. The bubble seeps discovered during the cruise originated from different vents situated some hundred meters apart from each other.

Based on image analysis of still photographs of emitted bubbles (Fig. 2a) the mean bubble diameter was $5.2 \mathrm{~mm}$ (range of 1-10 $\mathrm{mm}$ ) at the seafloor. Since this size determination was affected by image resolution limitations and the angled observation view, we used the mean bubble diameter of $5.2 \pm 1 \mathrm{~mm}$ for further volume calculation.

A $2 \mathrm{~m}$ thick bottom section of a bubble plume contained $\sim 3600$ bubbles with a total volume of $200 \mathrm{ml}(140-300 \mathrm{ml})$. The bubble volume is equivalent to $\sim 1.5(1.0-2.2)$ moles of methane on a $2 \mathrm{~m}$ bottom section of the plume (Fig. 2a), including compressibility. The compressibility modulus of methane is 0.75 at in situ conditions [45], i.e. the volume of 
methane per mole is decreased to $75 \%$ of the ideal gas volume under in situ conditions. This is a conservative estimate of the number of bubbles and the total volume since bubbles in the front hide those in the background. The volume error caused by a gas hydrate coating should be negligible since the volumetric gas to hydrate ratio changes from about 164:1 at surface conditions [46] to $0.98: 1$ at 125 bar (including methane compressibility). From video observations a mean bubble vertical velocity of about $31 \mathrm{~cm} \mathrm{~s}^{-1}\left(25-35 \mathrm{~cm} \mathrm{~s}^{-1}\right)$ was estimated for the core stream of three different bubble plumes. From one plume, a branch of small bubbles $(<3 \mathrm{~mm})$ was observed to separate from the downstream edge of the plume by turbulences and bottom currents. Rise velocities of those bubbles were considerably lower with values below $12 \mathrm{~cm} \mathrm{~s}^{-1}$. In addition, a small number of nonellipsoid objects drifted around with a low vertical velocity (apparently close to neutral buoyancy). We suspect that those objects were primarily gas hydrate particles (flakes), possibly containing inclusions of gaseous methane and/or sediment particles. The latter could have functioned as crystallization nuclei for the precipitation of gaseous methane into flakes.

Although observations were scaled by comparison with objects of known dimensions (e.g. manipulator of the ROV), the rice velocity estimates were affected by uncertainty from the angled point of view relative to the core bubble stream. Thus, we also used bubbles which were observed to break apart as an "internal scale" basing on more detailed studies showing that bubbles $\geq 2 \mathrm{~cm}$ in diameter start to disintegrate into smaller bubbles [19]. On the basis of these observations we estimate a methane flux of $\sim 200(80-360) \mathrm{mmol} \mathrm{s}^{-1}$ at a single vent, about an order of magnitude greater than the values obtained by optical means at 
bubble seeps at the upper edge of the hydrate stability zone in the Gulf of Mexico [19]. Assuming steady flow, an emission rate of 108 (42-182) tons methane $\mathrm{yr}^{-1}$ would be emitted by this vent. On the basis of the three observed vents, where similar bubble emission rates were observed, we suggest a discharge of gaseous methane to the water column of several hundred tons per year.

Our experience working with ROVs at the seafloor shows that the plumes easily can be missed: Bubble plumes were observed to expand with increasing altitude from a narrow stream of $\sim 20 \mathrm{~cm}$ diameter at the seabed. Bubble density decreased from $\sim 45$ bubbles $\mathrm{L}^{-1}$ at the outlet to approximately 1 and 0.2 bubbles $\mathrm{L}^{-1}$ at $18.5 \mathrm{~m}$ and $25.4 \mathrm{~m}$ altitude, respectively (Figs. 2 d, e). Further, the plume sometimes was slightly bent by the bottom current profile. At $50 \mathrm{~m}$ above the seafloor and higher, it was hard to track the bubbles visually using the ROV. It is possible, that the ROV thrusters disrupted the bubble stream or that bubbles froze-out as hydrate at the bottom of the ROV. From the acoustic observations (see below) one may infer additional sites, which, given the difficulties of ROV-based bubble plume observations, is not precluded by a lack of visual information.

Beside the discovery of focused gas emission, large areas of perforated sediments were observed at different locations (Fig. 2c). We interpret these structures to be indicative of additional episodic gas release since organisms able to create those structures were not found in sediment samples [47], although, no bubble release was observed visually.

Methane bubbles should dissolve rapidly in the ambient sea water which is highly undersaturated with respect to the methane bubble pressure $[12,21,48]$. Instead, the plume extended to at least $750 \mathrm{~m}$ into the water column (to $550 \mathrm{~m}$ water depth) as shown by the echo sounder both during the expeditions in 2002 and 2003 (Fig. 3a-c). The echograms 
revealed extensive acoustic anomalies in the water column above HMMV. In accordance to previous studies $[13,14,15]$, we interpret this as plume structures consisting primarily of gas bubbles which most likely were covered by gas hydrate [20,21]. Their survival in the water column coincided with the temperature-depth field of gas hydrate stability at the ambient sea water temperature (field below the green line in Fig. 4 a) [49]. Although different in shape, the plumes were found to be of similar size and height in 2002 and 2003, suggesting continuous emissions. In addition, passing the HMMV during the cruise ARK XX/1 with RV "Polarstern" in summer 2004 allowed a quick acoustic survey by the $38 \mathrm{kHz}$ echo sounder. The plume size and heights of up to $750 \mathrm{~m}$ (plume top: $500 \mathrm{~m}$ water depth) were similar to previous observations. Due to technical reasons these data [50] only could be recorded from the sea surface to $1000 \mathrm{~m}$ depth and, thus, are not included here.

The plume orientation is determined by the rise velocity and the current profile. Currents vary on an hourly time scale from tides and passing eddies [51]. Almost independent of the current regime, the acoustic footprint of the plume at the seabed extended 600 and almost $400 \mathrm{~m}$ in latitudinal and longitudinal direction, respectively, (Fig. 3c). Within this area, bubble seeps were visually observed in a region of $\sim 200 \mathrm{~m}$ diameter (Fig. 1). Taking the echo sounder's beam width of $7.1^{\circ}$ and a corresponding swath width at the seafloor of $\sim 150$ m (Fig. 3c, upper left) into account, additional bubble sites not detected by ROV surveys are likely. However, there are no additional data such as high resolution side scan sonar surveys to confirm this.

Optical transmission measurements and nephelometry (optical backscatter, complementary to transmission) during the hydro casts confirmed the existence of a plume of light scatterers higher in the upper water column (Fig. 4b). Three stations (PS64/380, 384, and 
386) within the plume and close to the bubble locations showed distinct hydrographic (temperature and salinity) and optical anomalies in water depths between 490 and $800 \mathrm{~m}$ as well as between $900 \mathrm{~m}$ depth and the seafloor. In contrast, no anomalies (black and gray graphs) were observed outside the plume. Similar to the height of the acoustically imaged plume, the optical signals (transmission and nephelometer) showed good coincidence of the plume's top with the calculated minimum depth of gas hydrate stability (dotted line in Fig. 4). Salinity (S) and temperature (T) depth profiles of the three stations within the plume, i.e., above the center of the HMMV differ significantly from the outer stations (Fig. 4a). From the seafloor to depths of $\sim 900 \mathrm{~m}, \mathrm{~T}$ and $\mathrm{S}$ values within the plume were almost constant, particularly in comparison to outside the plume. This indicates locally enhanced vertical water exchange which we interpret to be most likely explained by bubble-induced up-welling previously described for shallower sites $[12,19]$. This upwelling both increases the bubble rise velocity and entrains bulk water [52]. In this context it is important to notice, that the rising water mass develops considerable upward momentum. Above $900 \mathrm{~m}$ depth, $\mathrm{T}$ and $\mathrm{S}$ profiles show a distinct offset within the plume compared to the outer stations. All CTD casts (both in and out of the plume) were performed within a circle of 1.5 km diameter above HMMV. Because the area around HMMV has little vertical relief (less than $20 \mathrm{~m}$ ), we exclude a topographic explanation. If the hydrographic differences inside and outside of the plume were caused either by seafloor topography or eddy-related current changes, the T-S relation of the individual water masses would not change. In contrast, the relationship between potential temperature and salinity (Fig. 5) shows significant anomalies for the in-plume profiles. Again we argue these are best explained by enhanced vertical mixing due to bubble-induced up-welling. The water column basically consists of Atlantic 
Water above $600 \mathrm{~m}$ depth and a branch of Arctic Intermediate Water below [33, 53] represented by the lower "linear" section (labeled AB on Fig. 5) of the T-S plot (salinity increased with temperature). Section (BC) above is characterized by salinities decreasing upwards with temperature due to "freshening" of surface water by precipitation and melt water from sea ice. Whereas different water masses plot well apart from each other in the T-S diagram, the admixture of neighboring waters connects those end-members. In accordance with [33], some of the T-S graphs measured outside the plume (black) showed a sharp discontinuity in the area of the salinity maximum (B) indicating stable water column stratification. In contrast, the rounded angle of all graphs obtained within the plume area (blue graphs) suggests an enhanced admixture in the zone around the salinity maximum at water depths as shallow as 100 and $300 \mathrm{~m}$. Accordingly, the temperature anomaly reaches up to $\sim 100 \mathrm{~m}$ water depth (Fig. 4a). Thus we propose that the rising bubbles enhance the vertical water exchange within and above the plume. Above the gas hydrate stability field bubbles dissolve but the vertically accelerated water masses continue to rise according to momentum conservation. Furthermore, the shallow T-S anomalies coincide with transmission and backscatter anomalies only recorded within the plume area and most pronounced in depths between 50 and $150 \mathrm{~m}$ (Fig. 4b). It is highly unlikely that bubble ebullition occurs from the dissolved methane plume because methane concentrations were well below saturation. Thus, we hypothize this effect reflects the extension of the bubbleinduced upwelling to shallow water depths and propose that this mechanism can allow dissolved methane originating from HMMV to escape to the atmosphere. This process would be further enhanced by storm-induced deep mixing as occurs frequently during autumn and winter in the North Atlantic [54]. 
Gas analysis revealed that the gas released from the HMMV was almost pure methane $(>99.9 \%)$. Conspicuously high bottom water methane concentrations of up to $>10^{4} \mathrm{nmol} \mathrm{L}-1$ were measured in the central part of HMMV (Fig. 4c). Towards the upper water column (above $800 \mathrm{~m}$ depth), concentrations declined to about double background level (5-6 nmol $\mathrm{L}^{-1}$ ) showing a highly diluted, but significant methane anomaly. Bottom water methane concentrations of up to several hundred nmol $\mathrm{L}^{-1}$ southwest and southeast of the bubble sites indicate that dissolved methane from the plume diffused and was advected within the lower water by currents.

Stable carbon isotope measurements by Damm and Budéus [33] confirm that methane released from HMMV is distributed over a large area by currents rather than being microbially oxidized locally, i.e., advection time is short compared to the time scale of microbial oxidation. The isotopic signature $\delta^{13} \mathrm{C}$ of methane at the oceanic background level outside of the plume typically lies between $-45 \%$ and $-34 \%$ VPDB (referenced against Vienna Pee Dee Belemnite) [55]. Dissolved pore water methane and gas extracted from subsurface hydrate samples showed very low $\delta^{13} \mathrm{C}$ values of $-60.6 \%$ and $-59.2 \%$ VPDB, respectively [56]. The bottom water of HMMV's center showed mean methane isotopic signatures of $-61.6 \%$ (range of -63.8 to $-57.8 \% \delta^{13} \mathrm{C}$ ) [33]. Surprisingly, the mean $\delta^{13} \mathrm{C}$ values obtained from the lower and upper water column (above $800 \mathrm{~m}$ depth) were as low as the value of the hydrate methane with values of $-59.3 \%$ VPDB and -58.9 \%o VPDB, respectively. If significant microbial oxidation of methane had occurred within the plume, higher methane isotope values would have been expected due to enzymatic isotope fractionation. 
Furthermore, according to the isotopic signatures, potential rates of aerobic microbial methane oxidation measured by turnover of tritiated methane tracer were low in the bottom water above the central mud volcano with $<1 \%$ turnover of the methane inventory per day. Potential rates further decreased to $<0.1 \%$ per year in the deep water column. Potential rates generally were undetectable in the upper water column except for the surface sample. This suggests that the majority of the methane escapes the deep-sea and is mixed into the upper water column and that microbial methane turnover plays only a minor role, even in the bottom waters. Probably, the very low bottom water temperatures $\left(-1^{\circ} \mathrm{C}\right)$ suppressed microbial activity [11]. In other more temperate and stratified methane-rich waters like in the Black Sea, substantially higher microbial methane turnover rates have been detected [6].

In addition to bubble plume emission and diffusive flux of dissolved methane, advective discharge of methane-rich fluids from holes in the seafloor was observed at several sites (Fig. 6). To estimate this kind of methane flux, an acoustic flow meter, capable of measuring very low flow velocities was lowered into two vents. The vertical component of the flow within the holes was $1.2( \pm 0.3) \mathrm{cm} \mathrm{s}^{-1}$ in both vents. Based on methane concentrations of the fluids sampled by the ROV (32 and $126 \mu \mathrm{mol} \mathrm{l}^{-1}$ ), methane fluxes were estimated at 10 and 18 moles per day, respectively assuming continuous outflow from the vents (diameter $\sim 60$ and $\sim 40 \mathrm{~cm}$, respectively, estimates from image analysis). Assuming the presence of 10 to 100 similar structures in the central area based on detailed bathymetric and video surveys (not shown), the annual methane flux arising from channeled outflow of dissolved methane could amount to several tons of methane, which is 
of comparable order of magnitude as the diffusive flux of dissolved methane released from the sediments of HMMV [34]. Thus, with discharge rates of up to several hundred tons of methane, bubble discharge is much more important than diffusive and focused fluid discharge to the ocean, and especially with respect to its contribution to the atmosphere. There are individual hydrocarbon sources of greater importance, such as the Coal Oil Point seeps in the Santa Barbara Channel [17] emitting vastly greater amounts of methane. On the other hand, the HMMV was estimated to release up to one order of magnitude more methane than the sources quantified in the Gulf of Mexico [19]. Due to the efficient methane transfer from the deep to the mixed layer and the sea surface by hydrate skin protected bubble plumes and bubble-induced upwelling we propose that the estimated $10^{3}$ $10^{5}$ SMVs [2] and other deep methane sources may contribute significantly to the atmospheric methane budget.

\section{Conclusions and outlook}

Acoustic techniques allow the efficient location and identification of submarine gas emission, providing an appropriate tool for plume detection. In this study, acoustic surveys were confirmed by hydrographic and optical information, which showed that methane can be transferred from a deep-sea source into the upper water column by means of ascending methane bubbles. Bubble-induced upwelling creates an upward momentum of rising water enriched in methane that extends above the shallowest depth of the bubble plume and transporting dissolved methane into surface waters. Therefore, this mechanism suggests there is greater importance with respect to vertical methane flux from deep submarine 
sources than previously assumed. A large number of deep submarine methane sources like cold seeps and mud volcanoes likely exists also in temperate and high latitude regions, where favorable pressure and temperature conditions allow methane bubbles to be coated by a gas hydrate skin upon release. Our observations suggest that for the HMMV, gas bubble emission dominates over both diffusive discharge and the focused outflow of dissolved methane. Furthermore, the transfer of methane from deep sources to upper waters may allow some of the methane to reach the atmosphere, particularly during deep winter mixing of the surface ocean. Because, unlike gas bubbles and hydrate flakes, dissolved methane is more accessible for microbial oxidation, we assume that a portion of the diffusively released methane is oxidized close to the seafloor. Nevertheless, the un-oxidized portion is significant and is spread out by currents as suggested by the measured oxidation rates and by isotope data obtained from the target area.

Beside a more systematic effort to acoustically detect methane plumes, the development of algorithms and procedures for the acoustic quantification of methane plumes are needed. Previous approaches performed in shallow areas such as the Santa Barbara Channel [17] as well as recent efforts for acoustic plume quantification [18] need adapting for deep water conditions. Exchange and dissolution processes as well as the upwelling flow must be considered to estimate realistically the amount of methane transported to the surface ocean.

\section{Acknowledgements}

The Authors thank captain and crew of RV "Polarstern" and the Genavir team of ROV "Victor 6000" for their unremitting assistance. We are grateful to J. Rogenhagen (Fielax $\mathrm{GmbH}$ ) for help with acoustics, H. Rohr (Optimare $\mathrm{GmbH}$ ) for CTD and hydrographic 
measurements. We express our thanks to the Alfred Wegener Institute colleagues L. Baumann and M. Gensheimer for laboratory work, J. Wegner for technical assistance and G. Krause and G. Budéus for oceanographic consultancy. Furthermore, we greatly appreciate methane analyses performed by J.P. Donval (IFREMER) and the fruitful comments of B.B. Jørgensen on an earlier version of the manuscript. We thank I. Leifer and the other reviewer for constructive and valuable comments. This study was performed in the frame work of the AWI-IFREMER bilateral collaboration program and the UK-FranceGermany Tripartite Agreement for the Exchange of Major Marine Facilities. This is AWI publication No 15117. 


\section{References}

[1] O. Badr, S.D. Probert, P.W. O'Callaghan, Atmospheric methane: Its contribution to global warming, Appl. Energy 40 (1991) 273-313.

[2]. A.V. Milkov, Worldwide distribution of submarine mud volcanoes and associated gas hydrates, Mar. Geol. 167 (2000) 29-42.

[3] K.A. Kvenvolden, T.D. Lorenson, The global occurrence of natural gas hydrate, in:

C.K. Paull, W.P. Dillon (Eds.), Natural gas hydrates: occurrence, distribution, and detection, Geophys. Monogr. Ser. 124 (2001) 3-18.

[4] A.V. Milkov, R. Sassen, T.V. Apanasovich, F.G. Dadashev, Global gas flux from mud volcanoes: A significant source of fossil methane in the atmosphere and the ocean, Geophys. Res. Lett. 30 (2003) 1037, DOI:10.1029/2002GL016358.

[5] D.L. Valentine, D. C. Blanton, W. S. Reeburgh, M. Kastner, Water column methane oxidation adjacent to an area of active hydrate dissociation, Eel River Basin, Geochim. Cosmochim. Acta 65 (2001) 2633-2640.

[6] W.S. Reeburgh, B. Ward, S.C. Whalen, K.A. Sandbeck, K.A. Kilpatrick, L.J. Kerkhof, Black Sea methane geochemistry, Deep-Sea Res. 38 (1991) S1189-S1210.

[7] A.G. Judd, M. Hovland, L.I. Dimitrov, S. Garća Gil, V. Jukes, The geological methane budget at continental margins and its influence on climate change, Geofluids, 2 (2002) 109126.

[8] J. Lelieveld, P.J. Crutzen, F.J. Dentener, Changing concentration, lifetime and climatic forcing of atmospheric methane, Tellus, 50B (1998) 128-150. 
[9] Intergovernmental Panel on Climate Change (IPCC), Climate change 2001: The scientific basis. Contribution of Working Group I to the Third Assessment Report of the IPCC, J.T. Houghton, Y. Ding, D.J. Griggs, M. Noguer, P.J. van der Linden, X. Dai, K. Maskell, C.A. Johnson (Eds.), Cambridge University Press, Cambridge (2001) 881pp. [10] G. Rehder, R.S. Keir, E. Suess, M. Rhein, Methane in the northern Atlantic controlled by microbial oxidation and atmospheric history, Geophys. Res. Lett. 26 (1999) 587-590. [11] M.I. Scranton, P.G. Brewer, Consumption of dissolved methane in the dep ocean, Limnol. Oceanogr. 23 (1978) 1207-1213.

[12] I. Leifer, R. K. Patro, The bubble mechanism for methane transport from the shallow sea bed to the surface: A review and sensitivity study, Cont. Shelf Res. 22 (2002) 24092428.

[13] R. Merewether, M.S. Olsson, P. Lonsdale, Acoustically detected hydrocarbon plumes rising from 2-km depth in Guaymas Basin, Gulf of California, J. Geophys. Res. 90 (1985) $3075-3085$.

[14] C.K. Paull, W. Ussler III, W.S. Borowski, F.N. Spiess, Methane-rich plumes on the Carolina continental rise: Associations with gas hydrates, Geology 23 (1995) 89-92.

[15] K.U. Heeschen, A.M. Tréhu, R.W. Collier, Distribution and height of methane bubble plumes on the Cascadia Margin characterized by acoustic imaging, Geophys. Res. Lett. 30 (2003) 1643, doi:10.1029/2003GL016974.

[16] V.N. Egorov, Yu.G. Artemov, G.G. Polikarpov, S.B. Gulin, Evaluation of vertical extension of methane gas bubble streams from the bottom of the Black Sea by hydroacoustic method, Geophys. Res. Abstr. 7 (2005) 03791. 
[17] J.S. Hornafius, D. Quigley, B.P. Luyendyk, The world's most spectacular marine hydrocarbon seeps (Coal Oil Point, Santa Barbara Channel, California): Quantification of emissions, J. Geophys. Res. 104 C (1999) 20703-20711.

[18] J. Greinert, B. Nützel, Hydroacoustic experiments to establish a method for the determination of methane bubble fluxes at cold seeps, Geo-Mar. Lett. 24 (2002) 75-85.

[19] I. Leifer, I. MacDonald, Dynamics of the gas flux from shallow gas hydrate deposits: Interaction between oily hydrate bubbles and the oceanic environment, Earth Plan. Sci. Lett. 210 (2003) 411-424.

[20] D.R. Topham, The formation of gas hydrates on bubbles of hydrocarbon gases rising in seawater, Chem. Engin. Sci. 39 (1984) 821-828.

[21] G. Rehder, P.W. Brewer, E.T. Peltzer, G. Friedrich, Enhanced lifetime of methane bubble streams within the deep ocean, Geophys. Res. Lett. 29 (2002) 10.1029/2001GL013966.

[22] I. Leifer, J.F. Clark, R.F. Chen, Modifications of the local environment by natural marine hydrocarbon seeps, Geophys. Res. Lett. 27 (2000) 3711-3714.

[23] P.R. Vogt, H. Fleming, E. Sundvor, K. Crane, S. Pfirman, A. Shor, SeaMarc II and associated geophysical investigation of the Knipovich Ridge, Molloy Ridge fracture zone, Spitsbergen/Barents/Norwegian continental margin and extinct Aegir Ridge (Norway Basin); Part III, Synthesis of sedimentary processes, EOS 72 (1991) 232.

[24] Y.A. Bogdanov, A.M. Sagalevich, P.R. Vogt, J. Mienert, E. Sundvor, K. Crane, A.Y. Lein, A.V. Egorov, V.I. Peresypkin, G.A. Cherkashev, A.V. Gebruk, G.D. Ginsburg, D.V. 
Voitov, The Haakon Mosby mud volcano in the Norwegian Sea; results of multidisciplinary studies with manned submersibles, Oceanology 39 (1999) 374-380. [25] M. Klages, B. Mesnil, T. Soltwedel, A. Christophe, The Expedition "AWI" of RV "L'Atalante" in 2001, Rep. Pol. Mar. Res. 422 (2002) 1-65. [26] A.V. Milkov, P.R. Vogt, K. Crane, A.Y. Lein, R. Sassen, G.A. Cherkashev, Geological, geochemical, and microbial processes at the hydrate-bearing Håkon Mosby mud volcano: a review, Chem. Geol. 205 (2004) 347-366.

[27] P.R. Vogt, J. Gardner, K. Crane, The Norwegian-Barents-Svalbard (NBS) continental margin: Introducing a natural laboratory of mass wasting, hydrates, and ascent of sediment, pore water, and methane, Geo-Mar. Lett. 19 (1999) 2-21.

[28] G. D. Ginsburg, A.V. Milkov, V.A. Soloviev, A.V. Egorov, G.A. Cherkashev, P.R. Vogt, K. Crane, T.D. Lorenson, M.D. Khutorskoy, Gas hydrate accumulation at the Håkon Mosby Mud Volcano Geo-Mar. Lett. 19 (1999) 57-67.

[29] P.R. Vogt, K. Crane, E. Sundvor, B. O. Hjelstuen, J. Gardner, F. Bowles, G.

Cherkashev, Ground-Truthing 11- to $12-\mathrm{kHz}$ side-scan sonar imagery in the NorwegianGreenland Sea: Part II: Probable diapirs on the Bear Island fan slide valley margins and the Vøring Plateau, Geo Mar. Lett. 19 (1999) 111-130.

[30] J.S. Laberg, T.O. Vorren, A late Pleistocene submarine slide on the Bear Island trough mouth fan, Geo Mar. Lett. 13 (1993) 227-234.

[31] A. Milkov, P. Vogt, G. Cherkashev, G. Ginsburg, N. Chernova, A. Andriashev, GeoMar. Lett. 19 (1999) 38-47. 
[32] A. Boetius, K. Ravenschlag, C. Schubert, D. Rickert, F. Widdel, A. Gieseke, R. Amann, B.B. Jørgensen, U. Witte, O. Pfannkuche, A marine microbial consortium apparently mediating anaerobic oxidation of methane, Nature 407 (2000) 623-626.

[33] E. Damm, G. Budéus, Fate of vent-derived methane in seawater above the Håkon Mosby mud volcano (Norwegian Sea), Mar. Chem. 82 (2003) 1-11.

[34] E.J. Sauter, M. Schlüter, J.-L. Charlou, S.I. Muyakshin, A. Boetius, E. Damm, M. Klages, J.-P. Foucher, Estimating the importance of different pathways of methane discharge from deep-sea submarine sources, Geophys. Res. Abstr. 7 (2005) 04559. [35] A.Y. Lein, N.V. Pimenov, A.S. Savvichev, G.A. Pavlova, P.R. Vogt, Y.A. Bogdanov, A.M. Sagalevich, M.V. Ivanov, Methane as a source of organic matter and carbon dioxide of carbonates at a cold seep in the Norway Sea, Geochem. Intern. 38 (2000) 232-245. [36] A. Sam, C.O. Gomez, J.A. Finch, Axial velocity profiles of single bubbles in water/ frother solutions, Int. J. Miner. Process. 47 (1996) 177-196.

[37] G. Budéus, W. Schneider, In-situ temperature calibration: remark on instruments and methods, WOCE Newslett. 30 (1998) 16-18.

[38] M. Schlüter, E.J. Sauter, C.E. Andersen, H. Dahlgaard, P. Dando, Spatial Distribution and Budget for Submarine Groundwater Discharge in Eckernförde Bay (W-Baltic Sea), Limnol. Oceanogr. 49 (2004) 157-167.

[39] J.L. Charlou, J.P. Donval, Hydrothermal methane venting between 12 degrees $\mathrm{N}$ and 26 degrees N along the Mid-Atlantic Ridge, J. Geophys. Res. 98 (1993) 9625-9642.

[40] J. L. Charlou, Y. Fouquet, H. Bougault, J.P. Donval, J. Etoubleau, P. Jean-Baptiste, A. Dapoigny, P. Appriou, P.A. Rona, Intense $\mathrm{CH}_{4}$ plumes generated by serpentinization of 
ultramafic rocks at the intersection of the 15 degrees $20^{\prime} \mathrm{N}$ fracture zone and the MidAtlantic Ridge, Geochim. Cosmochim. Acta 62 (1998) 2323-2333.

[41] Z. Duan, N. Møller, J. Greenberg, J.H. Weare, The prediction of methane solubility in natural waters to high ionic strength from 0 to $250^{\circ} \mathrm{C}$ and from 0 to $1600 \mathrm{bar}$, Geochim. Cosmochim. Acta 56 (1992) 1451-1460.

[42] E.J. Sauter, M. Schlüter, J. Wegner, E. Labahn, A routine device for high resolution bottom water sampling, J. Sea Res., in press.

[43] F.T. Thwaites, A.J. Williams 3rd, Development of a Modular Acoustic Velocity Sensor, Oceans 96 (1996) 607-612.

[44] J.-P. Foucher, unpublished data.

[45] K. Schaefer, G. Beggerow, J. d'Ans, J. Bartels, H. Landolt, R. Börnstein, Zahlenwerte und Funktionen aus Physik, Chemie, Astronomie, Geophysik und Technik (Numbers and functions from physics, chemistry, astronomy, geophysics, and technics, in german), Vol. 2, Part 1, Springer, Berlin, 1971, 944 pp.

[46] D.W. Davidson, M.D. El-Defrawy, M.O. Fulgem, A.S. Judge, Natural gas hydrates in northern Canada, 3rd Int. Conf. on Permafrost, Proc., 1978, pp. 938-943.

[47] A. Gebruk, personal communication.

[48] I.R. MacDonald, I. Leifer, R. Sassen, P. Stine, R. Mitchell, N. Guinasso Jr., Transfer of hydrocarbons from natural seeps to the water column and atmosphere, Geofluids 2 (2002) 95-107. 
[49] E.T. Peltzer, P.G. Brewer, Practical physical chemistry and empirical predictions of methane hydrate stability, in: M.D. Max (Ed.), Natural Gas Hydrate in Oceanic and Permafrost Environments, Kluwer, Dordrecht, 2000, pp. 17-28.

[50] E.J. Sauter, T. Soltwedel, unpublished data.

[51] H. M. van Aken, G. Budéus, M. Hähnel, The anatomy of the Frontal Zone in the Greenland Sea, J. Geophys. Res. 100 (1995) 15999-16014.

[52] T.J. McDougal, Bubble plumes in stratified environments, J. Fluid Mech. 4 (1978) $655-672$.

[53] J. Blindheim, Arctic intermediate water in the Norwegian sea, Deep-Sea Res. 37 (1990) 1475-1489.

[54] J. Pailet, M. Arhan, Ocean ventilation in the eastern North Atlantic, J. Phys. Oceanogr. 26 (1996) 2036-2052.

[55] M. J. Whiticar, Carbon and hydrogen isotope systematics of bacterial formation and oxidation of methane, Chem. Geol. 161 (1999) 291-314.

[56] A. Lein, P. Vogt, K. Crane, A. Egorov, M. Ivanov, Chemical and isotopic evidence for the nature of the fluid in CH4-containing sediments of the Haakon Mosby Mud Volcano, Geo-Mar. Lett. 19 (1999) 76-83.

[57] C. Edy, H. Bisquay, J.-P. Foucher, J. Opderbecke, P. Simeoni, A.-G. Allais, A. Beyer, K. Jerosch, R. Rathlau, Microbathymetry of the Håkon Mosby Mud Volcano off northern Norway: Results of a ROV-born multibeam survey, Geophys. Res. Abstr. 6 (2004) 04619. 


\section{Figure Legends:}

Figure 1: Map of the Håkon Mosby Mud Volcano situated at the Norwegian-BarentsSpitzbergen continental margin between Norway and Spitzbergen. The map shows the gas bubble locations observed by means of the ROV "Victor 6000" (white circles), hydrographic stations outside the plume (black squares) and the trajectories of the drift CTD stations within the plume (see map legend). The high resolution bathymetry [57] was obtained by multibeam surveys by the ROV "Victor $6000 "$.

Figure 2: Still picture of bubble discharge location taken at 12.7 .2003 by the still camera of the ROV "Victor 6000" (a). Zoomed section of a still photograph showing discharged bubbles $\sim 1 \mathrm{~m}$ above the seafloor (b). Video image of perforated sediments indicative of transient gas release (c). Bubbles at 18.5 and $25.4 \mathrm{~m}$ above the seafloor observed by the main video camera of "Victor 6000" (d, e). (e) was thresholded to binary for automated bubble analysis.

Figure 3: Acoustic images of methane plumes in the water column. Echograms were obtained by means of a Simrad ${ }^{\mathrm{TM}}$ EK60 fishery echo sounder onboard RV "Polarstern" during Expeditions ARK XVIII/1b in 2002 (a), and ARK XIX/3b in 2003 (b). Horizontal plume extension at different times (c). The shape of the plume was mapped at 3 time intervals (green, red, and blue), each estimated by 4-6 transects across the plume center. Solid areas indicate the footprint of the acoustically observed plume at the seafloor; dashed lines mark the maximal horizontal spreading in the water column. The echo sounder footprint is indicated in the upper left for 1250 (larger) and $600 \mathrm{~m}$ water depth (smaller). 
Figure 4: Water column profiles of potential temperature and salinity (a). The hydrographic profiles of the three center stations PS64/380, 384, and 386 (potential temperature: bluish and salinity: reddish colors) can be clearly distinguished from profiles obtained outside the plume (potential temperature: black and salinity: gray) by a distinct offset assumed due to bubble induced up-welling. Transmission (plume profiles: bluish colors, outside plume: black) and optical backscatter (inside plume: reddish colors, outside: black) behave in complementary manner (b). Methane concentrations inside (red) and outside (black) the bubble stream (c). Methane analysis by headspace technique from water samples [38], (diamond symbols) and by purge and trap technique from poisoned subsamples immediately after the cruise $[39,40]$ (square symbols). See text for details.

Figure 5: Potential temperature - salinity plot above Håkon Mosby Mud Volcano. The bluish profiles were obtained within, black profiles were obtained outside the plume. The properties of the Arctic Intermediate Water (lower water column), Atlantic water (upper water column, salinity maximum), and the surface mixed layer are indicated by A, B, and C, respectively. See text for details.

Figure 6: Picture of vertical flow measurement with MAVS3 travel time current meter at a fluid discharge location. The current meter was positioned at different heights above the seafloor and at different depths inside the hole to distinguish flows of different direction. Further description of the MAVS3 is given in ref. [43]. Water samples were taken at the same location for methane analysis in order to calculate methane discharge rates. 


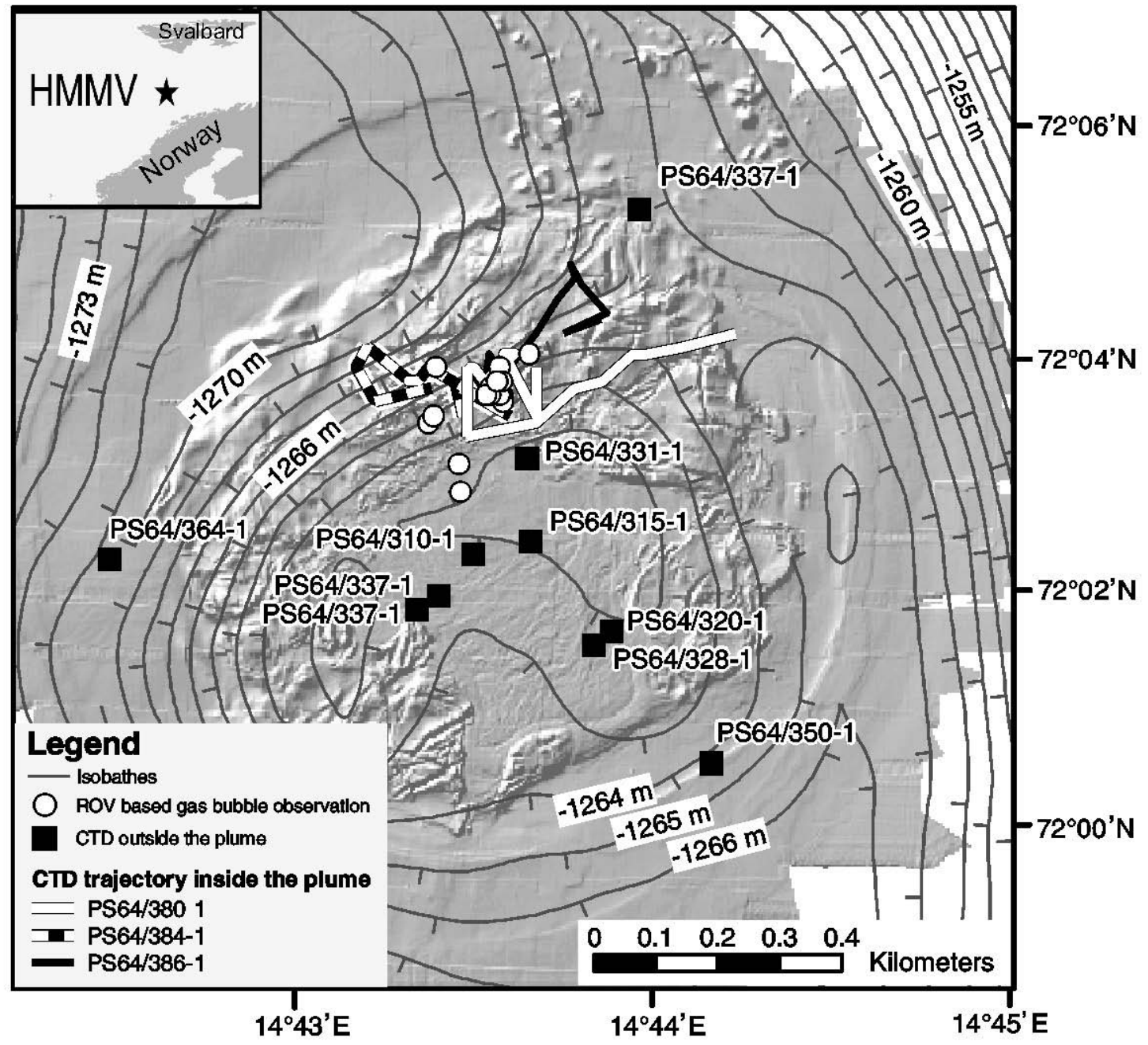

Fig. 1 

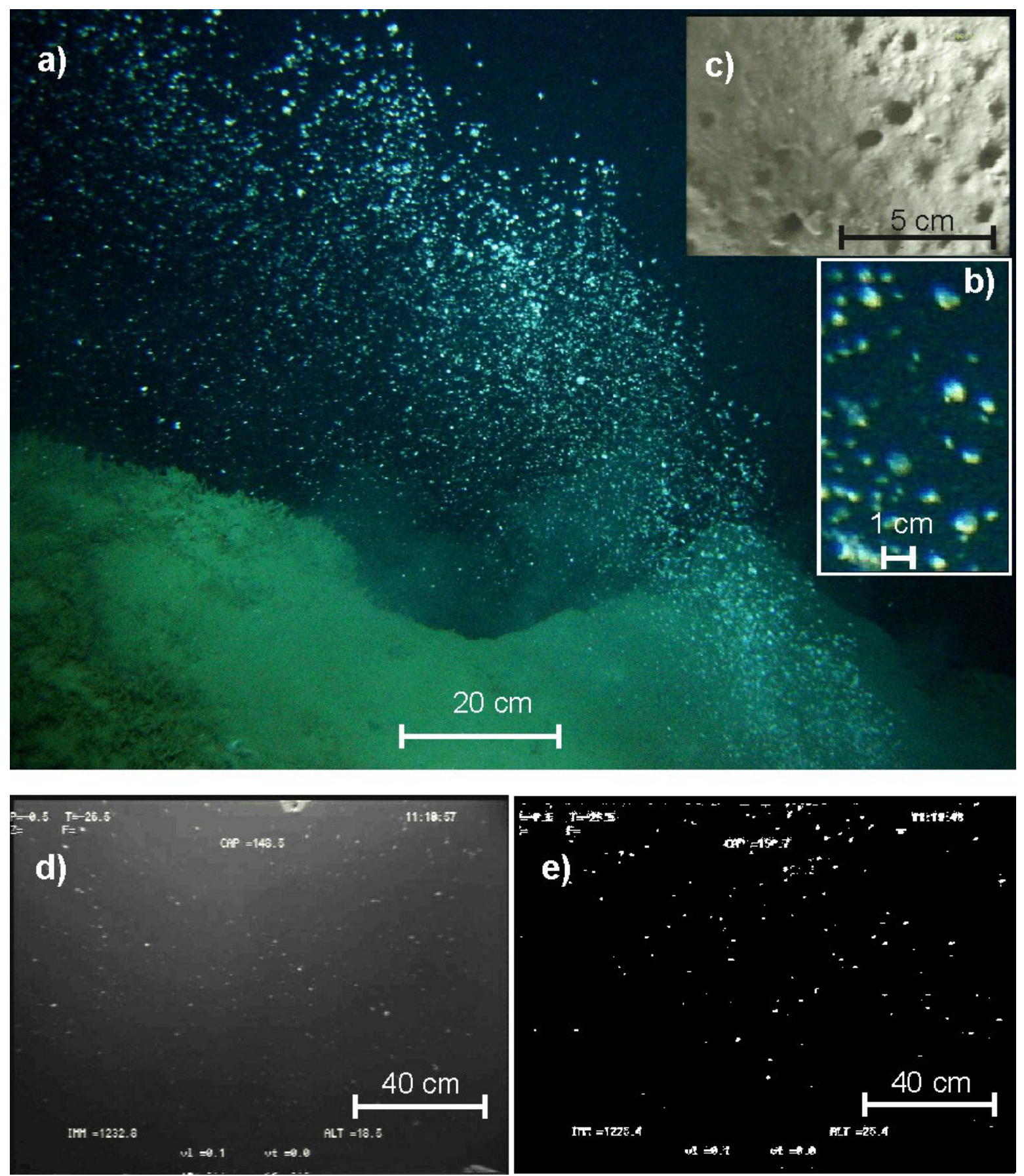

Fig. 2 

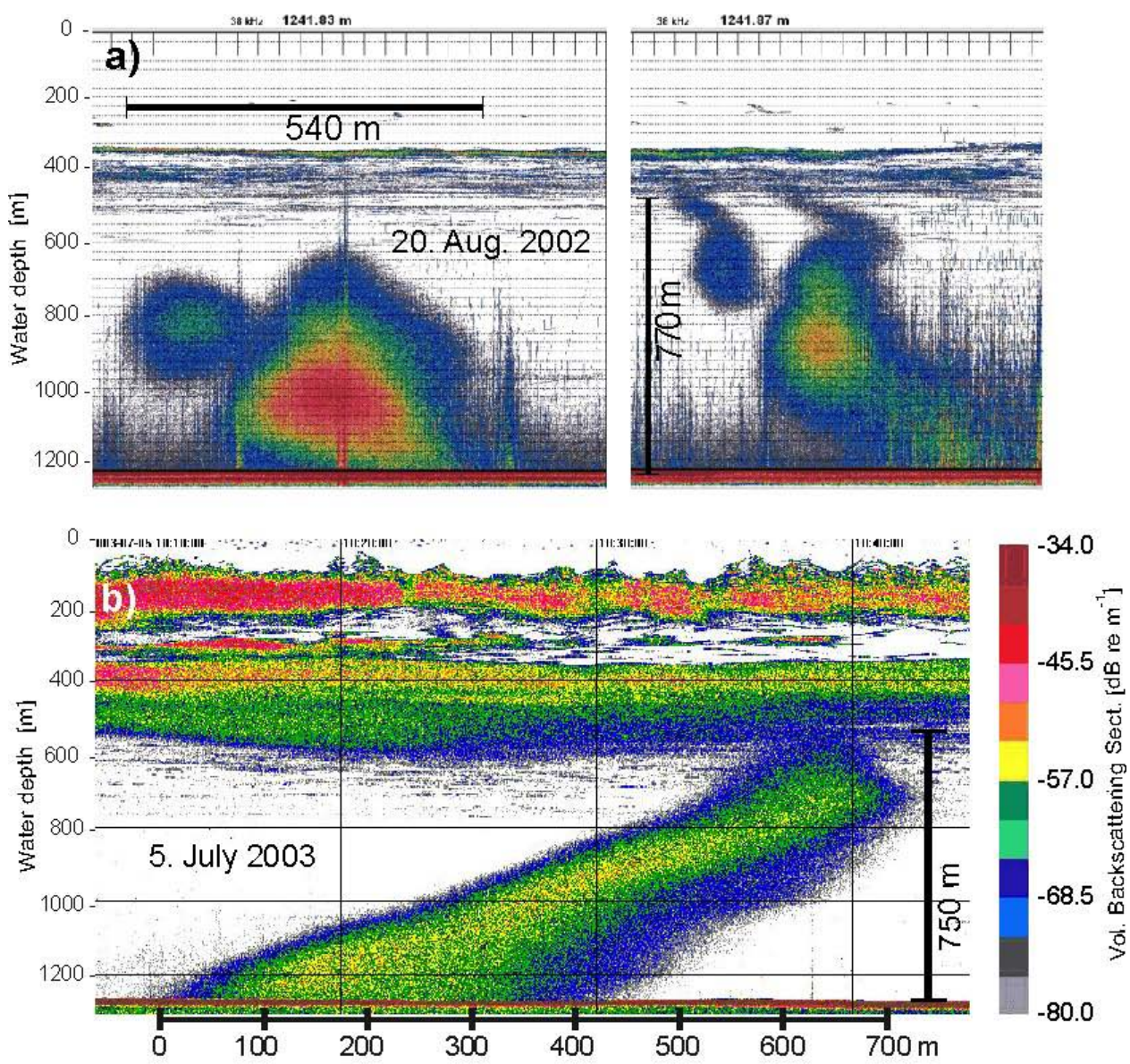

c)

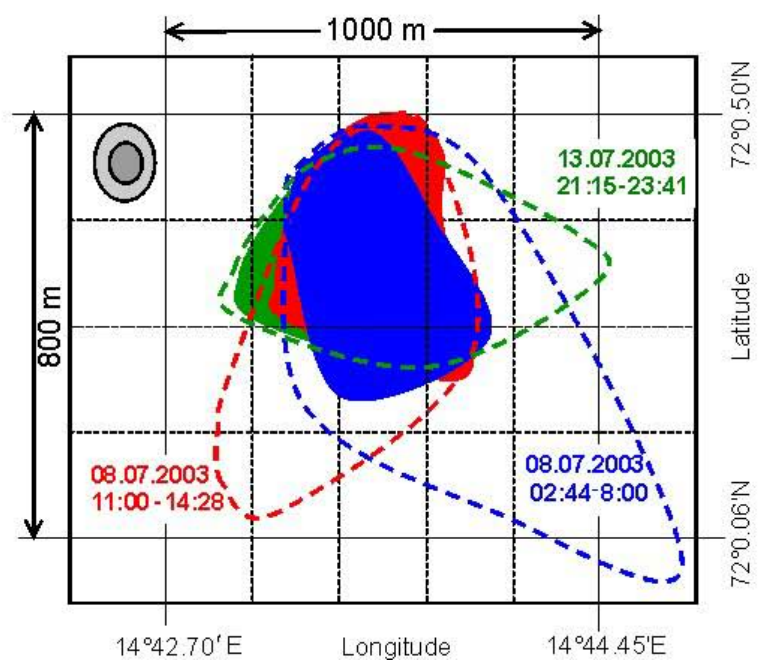

Fig. 3 


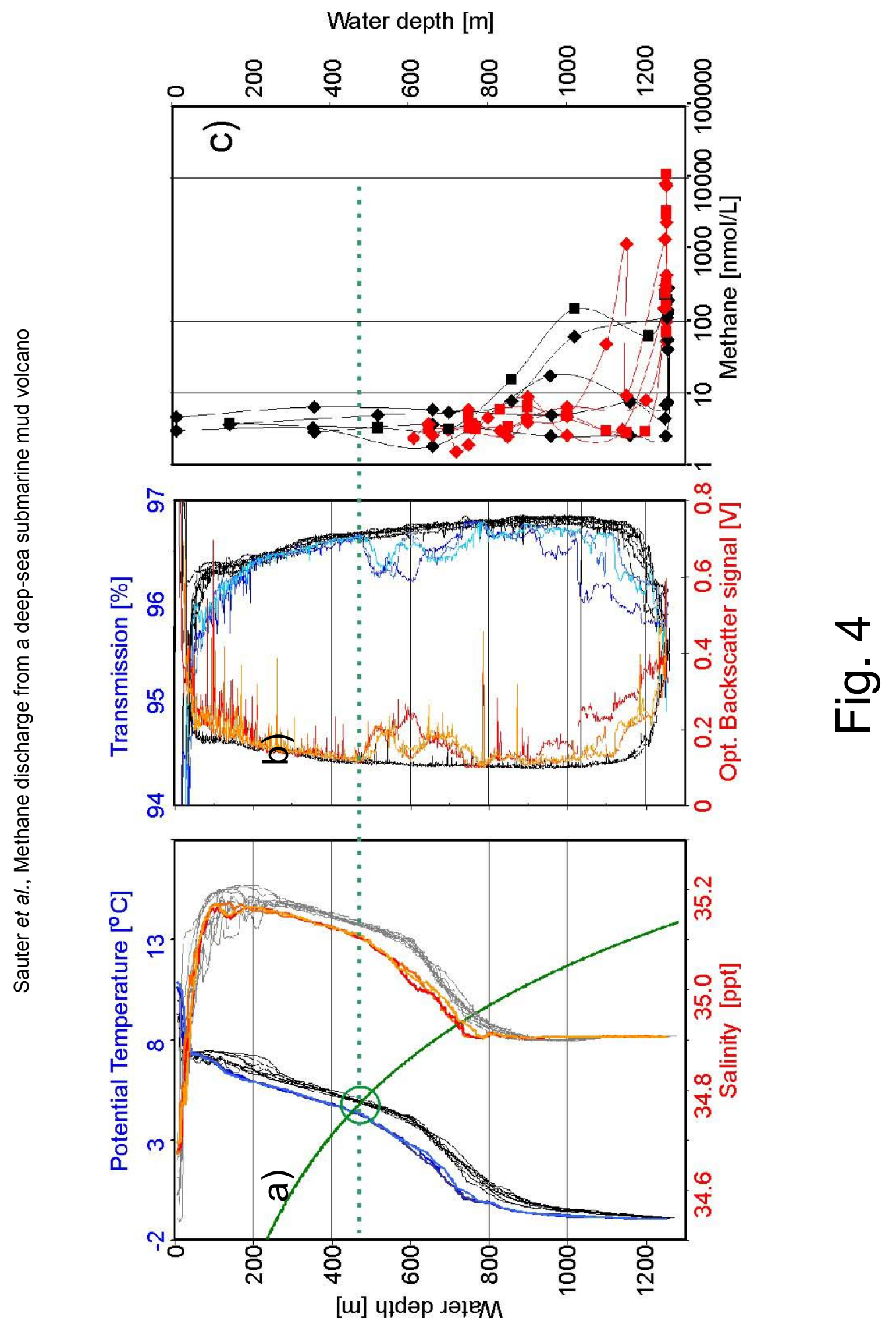




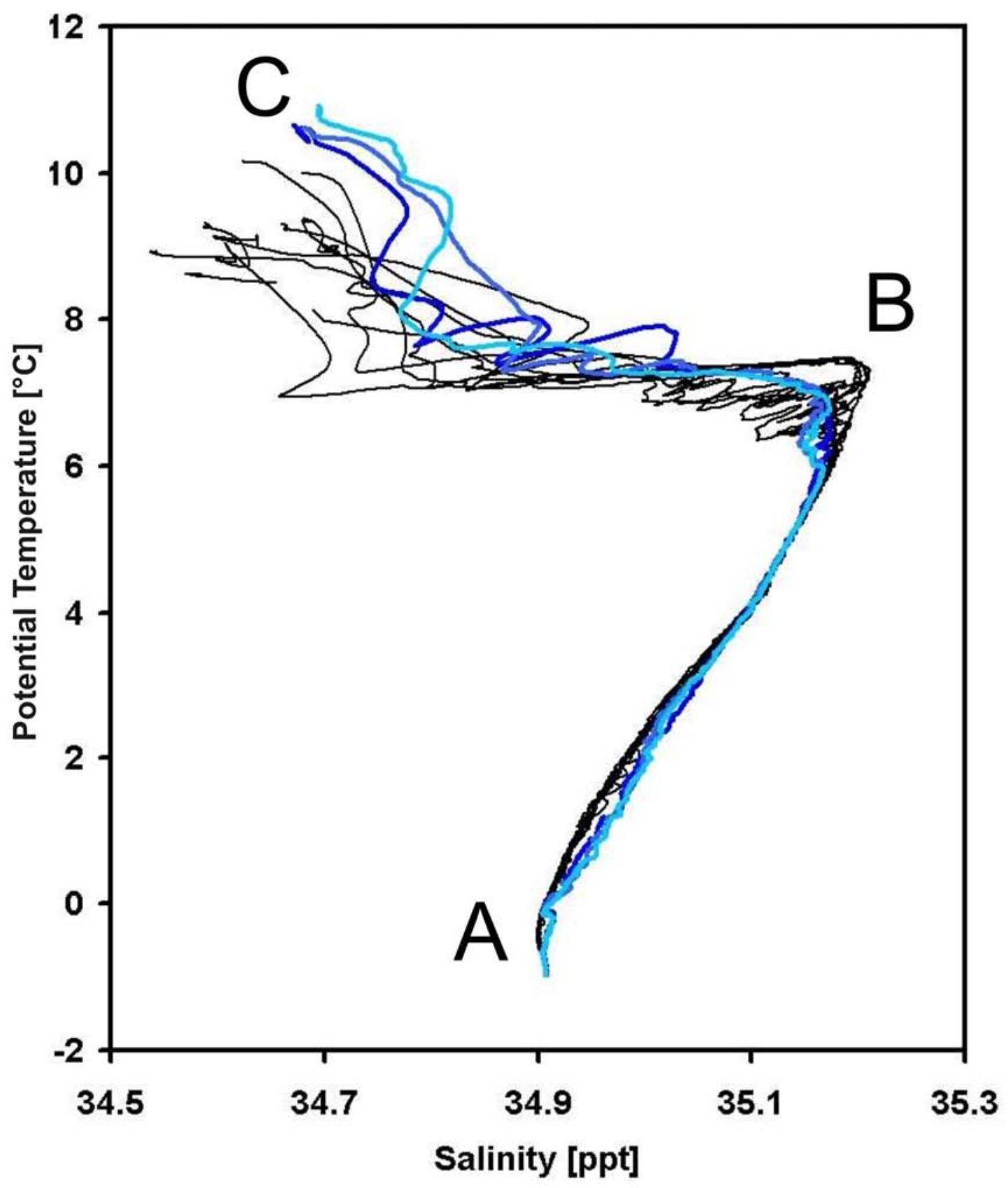

Fig. 5 


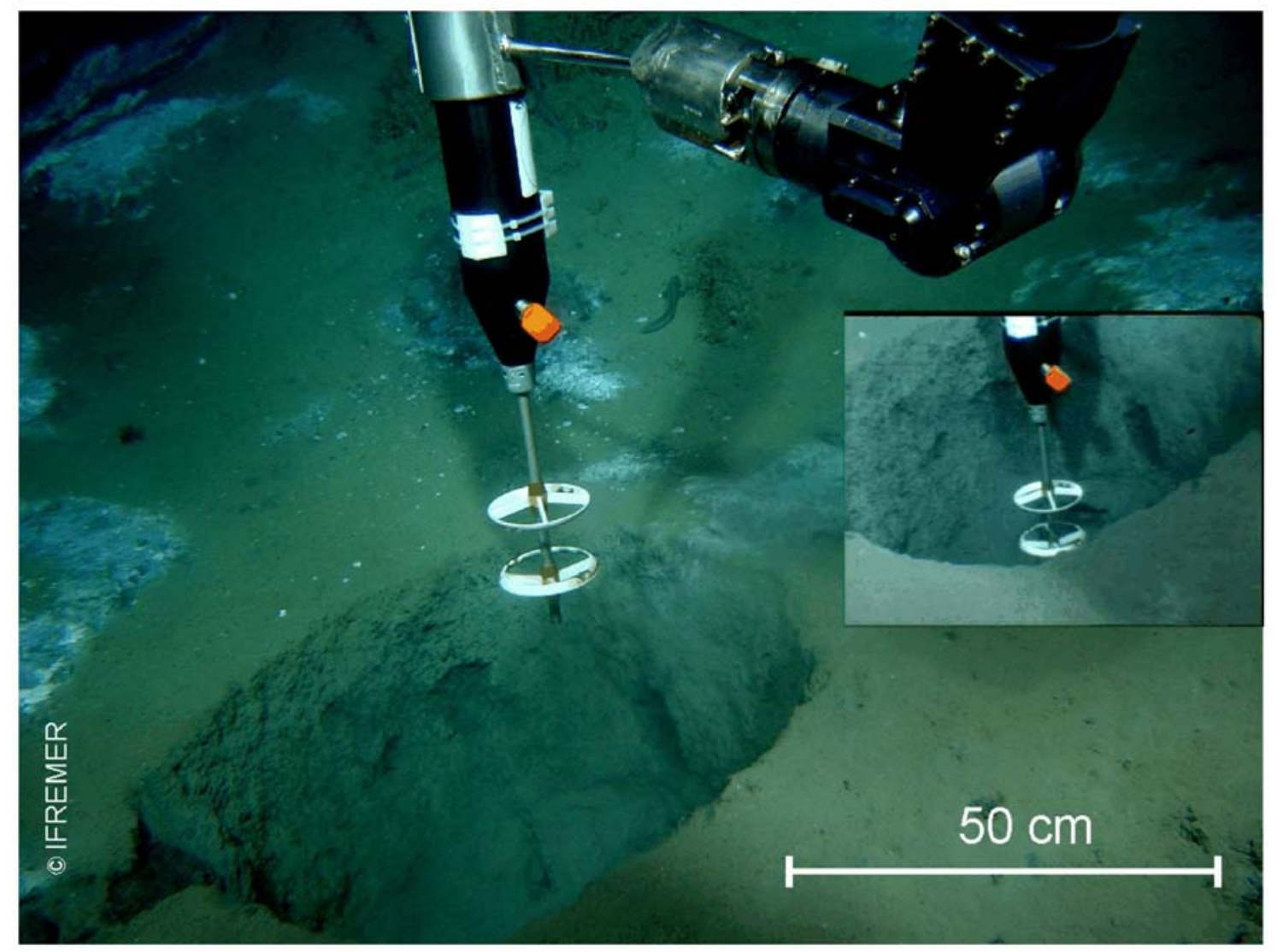

Fig. 6 